\title{
O impacto do "milagre econômico" sobre a classe trabalhadora segundo a imprensa alternativa
}

\author{
Ana Elisa Lara Paulino ${ }^{1}$ \\ https://orcid.org/0000-0003-0125-3985 \\ ${ }^{1}$ Universidade do Sagrado Coração, Curso de História, Bauru, SP, Brasil
}

\section{O impacto do "milagre econômico" sobre a classe trabalhadora segundo a imprensa alternativa}

Resumo: O presente artigo objetiva compreender, por meio da imprensa alternativa, as consequências que as classes trabalhadoras sofreram durante o período do chamado "milagre econômico" (1968-1973), período que buscava principalmente a ascensão das empresas multinacionais e da elite privilegiada do país. Através de uma análise realizada por publicações dos Jornais Politika, Opinião e O Pasquim, referente aos anos de 1971 e 1973, é possível compreender os diferentes tipos de situações econômicas e sociais pelas quais as classes eram submetidas e quais as atitudes que tomavam perante a conjuntura. Além de publicações da imprensa alternativa como fonte primária, realizou-se revisão bibliográfica e análise de dados estatísticos da economia da época. No entanto, é possível perceber que em busca de uma economia em crescimento, a força de trabalho do proletariado era intensivamente explorada por grupos dominantes e pelo Estado, descartando a qualidade de vida e direitos trabalhistas.

Palavras-chave: Ditadura Militar. Milagre Econômico. Classe trabalhadora. Imprensa Alternativa.

The impact of the "economic miracle" on the working class according to the alternative press.

Abstract: This article aims to understand, through the alternative press, the consequences that the working classes suffered during the period of the so-called "economic miracle" (1968-1973), a period that mainly sought the rise of multinational companies and the country's privileged elite. Through an analysis carried out by publications of the newspapers Politika, Opinion and O Pasquim, referring to the years of 1971 and 1973, it is possible to understand the different types of economic and social situations by which the classes were subjected and what attitudes they took before the conjuncture. In addition to publications from the alternative press as a primary source, a bibliographic review and analysis of statistical data on the economy of the time was carried out. However, it is possible to see that in search of a growing economy, the proletariat's workforce was intensively exploited by dominant groups and the state, discarding the quality of life and labor rights.

Keywords: Military Dictatorship. Economic Miracle. Working Class. Alternative Press.

Recebido em 20.05.2020. Aprovado em 03.06.2020. Revisado em 05.07.2020.

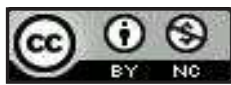

(C) O(s) Autor(es). 2020 Acesso Aberto Esta obra está licenciada sob os termos da Licença Creative Commons Atribuição-NãoComercial 4.0 Internacional (https://creativecommons.org/licenses/by-nc/4.0/deed.pt_BR), que permite copiar, distribuir e reproduzir em qualquer meio, bem como adaptar, transformar e criar a partir deste material, desde que para fins não comerciais e que você forneça o devido crédito aos autores e a fonte, insira um link para a Licença Creative Commons e indique se mudanças foram feitas. 


\section{Introdução}

O chamado milagre econômico brasileiro ocorreu no período linha dura da ditadura militar do país, entre os anos de 1968 até 1973, ocasião que teve como presidentes Artur da Costa e Silva até 1969 e Emílio Garrastazu Médici até o final do milagre, período esse conhecido também como anos de chumbo. Neste artigo, analisaremos o impacto do chamado "milagre econômico" sobre a classe trabalhadora industrial, em destaque dos Estados de São Paulo e Rio de Janeiro, por meio da imprensa alternativa, especialmente os Jornais Politika, Opinião e $O$ Pasquim.

O termo "milagre econômico" foi muito utilizado principalmente pela imprensa oficial nacional e internacional, buscando explicar o crescimento rápido de dados da economia brasileira no período referido. Segundo Habert (1992, p.11), "as empresas multinacionais consideravam o Brasil área segura e rentável para seus investimentos", sendo assim, a princípio, as indústrias multinacionais mais estimuladas para investir no Brasil foram as automobilísticas, seguidas das químicas e farmacêuticas. Contudo, o desenvolvimento maior foi o das indústrias estrangeiras de bens duráveis (elétrica, autopeças, veículos, eletrodomésticos) e mesmo que o desenvolvimento maior tenha sido na área de bens duráveis, a indústria em geral tive seu crescimento intensificado.

De acordo com Habert (1992, p. 12), "Ao final de cada balanço econômico, o governo e a burguesia parabenizavam-se pelos números, pelo 'clima de calma e tranquilidade' que diziam existir no País e, é claro, pelas altíssimas taxas de lucros obtidos". O Brasil passa a ser então um país de aparências, onde só eram observados e levados em conta dados da economia industrial pela ótica da burguesia, deixando de lado a análise socioeconômica de quem realizava a real produção interna do país, a massa de trabalhadores assalariados, que se encontrava mais da metade recebendo menos de um salário mínimo, e em péssimas condições sociais e de trabalho, sendo o Brasil um dos primeiros países em assuntos como subnutrição, mortalidade infantil e acidentes de trabalho (HABERT, 1992).

O desenvolvimento das empresas e o alto rendimento de capital da classe detentora dos meios de produção eram consequências justamente do descaso no qual o governo tinha com o proletariado e com a questão socioambiental do país, mantendo os salários sempre baixos, más condições de trabalho e de vida, depredação ecológica, e uma autoritária forma de governo. Quaisquer manifestações por melhorias sociais, ambientais e salariais eram respondidas de forma violenta e agressiva. Como destaca Oliveira (1987, p. 28):

Na periferia de São Paulo cerca de $80 \%$ dos domicílios não eram servidos por rede de esgoto, enquanto 54\% não possuíam rede de água. [...]. Os índices de mortalidade infantil também dão conta da deterioração da vida do trabalhador nesse período de milagre, quando, por exemplo, se compara que entre as décadas de 40 e 50 a taxa de mortalidade infantil diminui de $30 \%$, e na década seguinte decresce de $32 \%$, enquanto que, ao contrário, entre 60/75 ocorre acréscimo de $37 \%$.

Para se entender os impactos do boom da economia brasileira, especialmente sobre a classe trabalhadora, devemos também analisar o contexto geral no qual o país estava vivendo em relação à sua economia, à sua política e principalmente sobre as condições de vida da população. Na questão econômica, o país divulgava seus recordes estatísticos, no entanto, contava com um grande aumento na dívida externa, que saltara de 3,9 bilhões no começo do milagre para 12,5 bilhões no final, além do crescimento da desigualdade social, com $78,8 \%$ da população ganhando menos do que dois salários mínimos (ALVES, 2005).

Em sua vertente política, o governo da época era extremamente repressivo, qualquer movimentação trabalhista ou contestação governamental era respondida de forma violenta por dirigentes do Estado. As censuras também eram uma característica forte do governo, fazendo com que os jornais de imprensa alternativa tivessem grande parte de suas publicações vetadas, principalmente textos críticos que destacassem o sistema trabalhista dando voz ao operariado. Dessa forma, a conscientização da sociedade perante questões políticas e socioeconômicas se tornava praticamente impossível. De acordo com Abreu (2000, p. 80), "Os burocratas do Departamento de Censura da Polícia Federal exerciam a tarefa de simultaneamente, zelar pela "família brasileira' e evitar qualquer tipo de contestação política - assumida ou metafórica - que pusesse em xeque o regime militar".

Em relação ao contexto social, depara-se com a massa da população à margem das preocupações do Estado nacional, em condições de trabalho e de vida deploráveis; as horas de trabalho necessárias para a compra de alimentação mensal foram respectivamente aumentadas. Em menos de dez anos a média mensal de horas de trabalho teve um profundo aumento, saltando de 65 horas e 05 minutos em 1959, para 101 horas e 35 minutos em 1968 (início do milagre), e intensificando-se ainda mais em 1973 (final do milagre), totalizando em 147 horas e 04 minutos a quantia necessária de horas trabalhadas para a compra da alimentação mensal mínima (ALVES, 2005). Além do aumento também do índice de subnutrição, de mortalidade infantil e de acidentes de trabalho, como afirma Habert (1992, p. 12-13): 
72 milhões de brasileiros (67\% da população) eram subnutridos. A taxa de mortalidade infantil aumentou não só nas regiões tradicionalmente atrasadas como também nas mais industrializadas [...] estima-se que dos 36 milhões de pessoas que compunham a PEA (População Economicamente Ativa), dois milhões foram vítimas de acidentes de trabalho.

Analisando todas essas questões, percebemos que o "milagre econômico", de milagroso não tinha nada, afinal o que levou a ser denominado dessa forma, foram basicamente três pilares:

O aprofundamento da exploração da classe trabalhadora submetida ao arrocho salarial, às mais duras condições de trabalho e à repressão política; a ação do Estado garantindo a expansão capitalista e a consolidação do grande capital nacional e internacional; e a entrada maciça de capitais estrangeiros na forma de investimentos e de empréstimos. (HABERT, 1992, p. 13-14).

Além de todos os problemas existentes, a classe trabalhadora foi submetida também ao chamado "arrocho salarial", no qual o salário mínimo não acompanhava o reajuste da inflação. Com isso, as empresas estrangeiras e as empresas privadas nacionais se sentiam atraídas pelo baixo preço da força de trabalho, logo a desigualdade social se tornou ainda maior. O governo não estava preocupado em realizar a distribuição de capital e consequentemente disponibilizar uma economia estável para toda a população, mas, sim, preocupado em aumentar o tamanho do bolo econômico ${ }^{1}$ para a classe privilegiadas. Foram realizados grandes investimentos estrangeiros concebidos pelo Programa Estratégico de Desenvolvimento (PED), resultando na maior dívida externa do país.

Entretanto, partir de revisão bibliográfica e conteúdos publicados em jornais da imprensa alternativa $(O$ Pasquim, Opinião e Politika), analisamos a seguir como o governo militar, por meio da censura, limitava as críticas e a divulgação de dados que expunham a real situação da classe trabalhadora.

\section{A resistência através de jornais da imprensa alternativa}

Para tratarmos a respeito dos conteúdos divulgados nos jornais da imprensa alternativa, devemos compreender que eles não eram compostos por operários em sua íntegra, mas também por pessoas que detinham amplo conhecimento intelectual com forte criticidade, e que consequentemente disponibilizavam em suas publicações discussões críticas em relação as situações socioeconômicas pelas quais a classe trabalhadora brasileira era submetida, além de temas da política atual da época e suas influências sobre a população.

Os impressos que analisamos neste artigo não fazem parte da grande imprensa ou imprensa oficial, mas, sim, da chamada imprensa alternativa ou imprensa nanica, que se opunha perante as atitudes do regime militar e davam notoriedade as classes populares. Essa imprensa buscava expor suas opiniões, fossem elas políticas, econômicas, sociais ou culturais, e tinha um papel indispensável na resistência brasileira perante a ditadura. É possível obter essa compreensão a partir das afirmações de Kucinski (2001, p. 05):

Em contraste com a complacência da grande imprensa para com a ditadura militar, os jornais alternativos cobravam com veemência a restauração da democracia e do respeito aos direitos humanos e faziam a crítica do modelo econômico. Inclusive nos anos de seu aparente sucesso, durante o chamado "milagre econômico", de 1968 a 1973. Destoavam, assim, do discurso triunfalista do governo ecoado pela grande imprensa, gerando todo um discurso alternativo. Opunham-se por princípio ao discurso oficial.

A imprensa alternativa se viabilizava de diversas formas de contestação, resistência e críticas a grande parte de atitudes tomadas pelo governo militar, mas para que todas essas questões fossem possíveis ela era constituída por quatro significados essenciais, são eles:

O de algo que não está ligado a políticas dominantes; o de uma oposição entre duas coisas reciprocamente excludentes; o de única saída para uma situação difícil e, finalmente, o do desejo das gerações dos anos de 1960 e 1970, de protagonizar as transformações sociais que pregavam (KUCINSKI, 2001, p. 05).

Buscaremos agora apresentar os periódicos e suas particularidades, explicitando seus objetivos, sua formação e algumas outras informações como, por exemplo, a quem suas publicações eram referidas e dirigidas.

O Pasquim foi um jornal brasileiro que teve seu lançamento no ano de 1969. Originário do Estado do Rio de Janeiro, contava com a colaboração de grandes nomes como o de Sérgio de Magalhães Gomes Jaguaribe (Jaguar) como editor de humor. Havia ainda o editor chefe Tarso de Castro, o editor gráfico Carlos Prósperi e mais, Ziraldo 
Alves Pinto, Henrique de Sousa Filho (Henfil), Millôr Fernandes, Luis Carlos Maciel, Paulo Francis, Ivan Lessa, Miguel Paiva, Claudius Ceccon e Sérgio Augusto, além de participações especiais como as de Caetano Veloso, Chico Buarque e Vinicius de Moraes (AUGUSTO; JAGUAR, 2006). Os ideólogos do jornal e os demais colaboradores discutiam questões sociais, políticas e econômicas pelas quais o país passava, um jornal composto por indivíduos que davam grande importância para debates que se voltavam para o operariado brasileiro e pelas péssimas condições que se encontravam, disponibilizando assim informações referentes as classes populares.

Diversos autores (CHINEM, 1995; KUCINSKI, 2001; AYMORE, 2016) compreendem que $O$ Pasquim foi um grande defensor da democracia e da liberdade, considerado o mais importante na luta pela liberdade de expressão e direito à informação, revolucionando a imprensa da época com seu humor e linguajar despojado, diferente da grande imprensa pela qual tinha repúdio. Com sua forma irreverente e diferente dos padrões de jornais da época, $O$ Pasquim tinha como leitores os mais diversos tipos de pessoas, mas principalmente jovens, artistas e pessoas que se opunham ao sistema ditatorial, em sua maioria sujeitos que não se incluíam na classe média, afinal essa classe era um dos alvos de críticas do jornal. Sendo um impresso muito forte e atrevido, resistiu a diversas formas de censura, à prisão de grande parte da redação, bombas em sua sede, e diversas outras formas de boicote, driblando a ditadura e encerrando suas atividades apenas em 1991.

Opinião foi um semanário que circulou entre os anos de 1972 a 1975, também originário do Rio de Janeiro. Segundo Kucinski (2001), o jornal foi liderado por Raimundo Pereira, financiado por Fernando Gasparian e contava em sua formação com diversos intelectuais e políticos da esquerda, além de conter a participação secreta da Ação Popular (AP). Fernando Gasparian, homem de grande apreço pelas questões políticas, vivendo-as sempre de forma intensa e ativa, sofreu árduo desgaste em razão do golpe de 1964. Após o golpe militar se manteve exilado durante três anos em Oxford e com a morte de Rubens Paiva ocorreu o impulso final para a ideia de lançar um jornal de oposição do

Durante o "milagre
econômico", em
contrapartida, a questão
social foi se agravando cada
vez mais, resultando em uma
população carente de atenção
do Estado, encontrando-se no
Brasil altos índices de
subnutrição, excessivos dados
de acidentes de trabalho,
surtos de doenças “6
verminoses intestinais,
malária, doença de chagas e
esquistossomose - e a fome.
Brasil, ideia essa que se efetiva futuramente. Raimundo Pereira, líder do semanário, foi um jornalista de grande prestígio profissional, perpassou por diversos jornais e revistas, sempre predominando a essência crítica em seus textos e publicações. Raimundo Pereira, no período do auge da ditadura militar brasileira, passou a compreender que "a grande imprensa havia adotado uma 'estratégia de adesão', havia se vendido 'no sentido mais amplo da palavra", (KUCINSKI, 2001, p. 163), foi assim que aceitou a proposta de criar um impresso, que passaria posteriormente a ser denominado Opinião.

Ao contrário de $O$ Pasquim, o Jornal Opinião não transformava o medo da sociedade brasileira em humor como forma de contestação, mas apresentava conteúdo editorial intelectualizado e com informações estrangeiras. Logo os vetos sobre suas publicações acabavam sendo mais recorrentes, pois o modo de apresentar suas noticiais eram de forma direta e explicita, sem o mesmo "jogo de cintura" do que $O$ Pasquim. Assim, podemos observar na Figura 1 censura em grande parte da página em que apresentava informações a respeito de crise política envolvendo políticos ativos em cargos públicos, além de partidos como MDB e ARENA, como podemos notar nos trechos a seguir:

O presidente Médici decretou terça-feira da semana passada a cassação do mandato e a suspensão dos direitos políticos, por 10 anos, do prefeito de Anápolis, João Batista Júnior, do MDB, e declarou o Município área de segurança nacional. A crise surgiu quando o governador Leonino Caiado criou a Comissão de Investigação Sumária para fazer uma devassa em várias Prefeituras do Estado. As lideranças políticas do Estado, em especial o senador Paulo Guerra e o governado Eraldo Gueiros, também receberam do presidente Médici recomendações para que a crise da ARENA em Pernambuco não prejudicasse a unidade do partido e nem tão pouco o momento sucessório [...] O exemplo da crise política na ARENA de Pernambuco contribuiu para acentuar divergências no Ceará, em São Paulo e no Paraná (OPINIÃO, 1973, p. 3). 
$\mathrm{O}$ veto sobre informações aprofundadas ou detalhadas a respeito de questões como essas da imagem eram recorrentes, afinal o governo militar se autovangloriava pela sua suposta calma, coerência e honestidade. Logo uma crise como essa não seria adequada e muito menos deveria ser exposta e apresentada à população, pois demonstraria desequilíbrio do sistema político brasileiro, podendo acarretar agitação de ideias e movimentação da população, algo no qual o sistema ditatorial não almejava.

\section{Figura 1 - Veto em página do jornal}

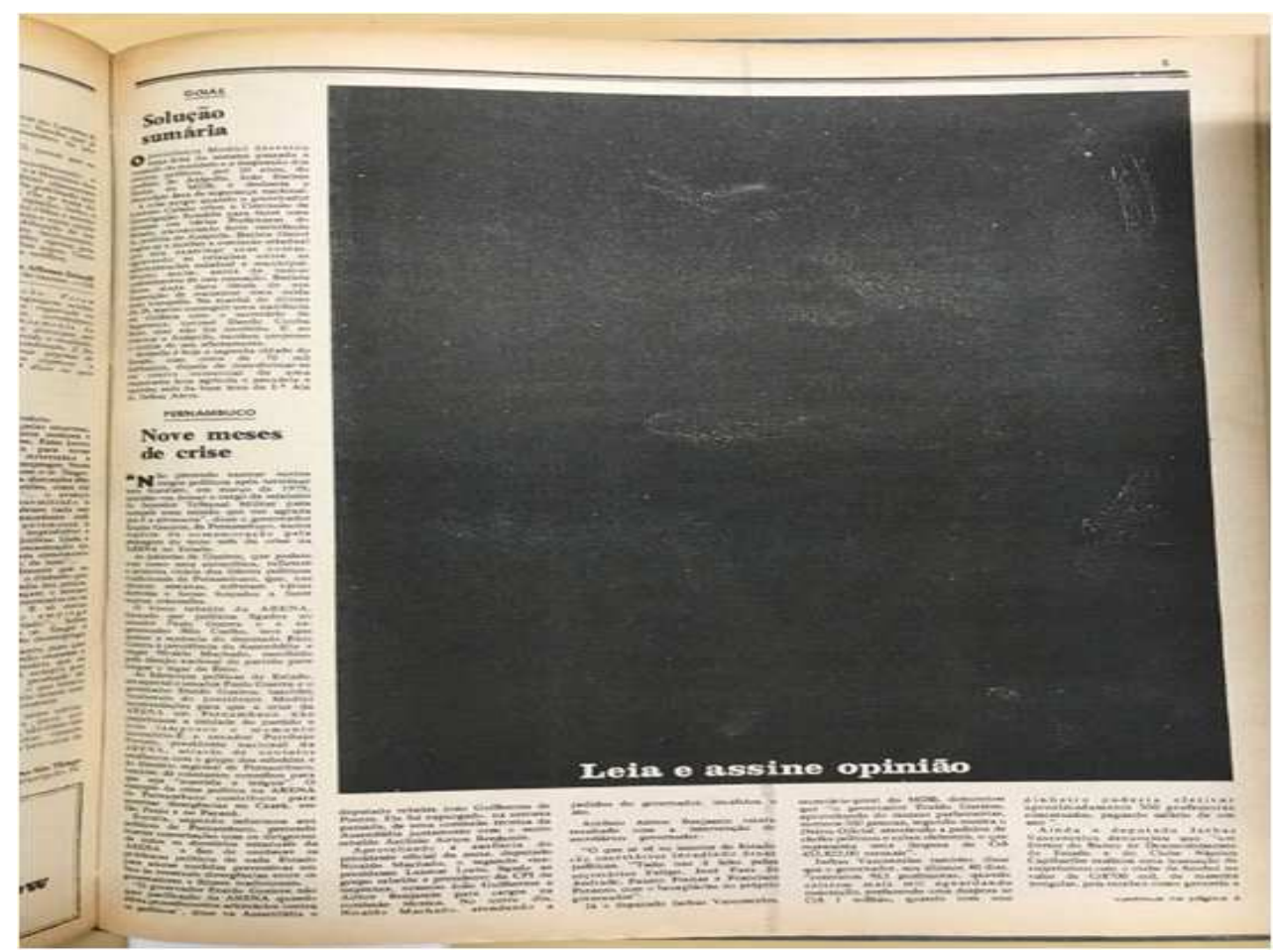

Fonte: Opinião (1973). Acervo: D’incao Instituto de Ensino, Bauru, SP.

O semanário continha público leitor em geral de jovens mais abastados, porém, que compreendiam as dificuldades das quais o Brasil vinha enfrentando, e dava notoriedade à classe trabalhadora. Seu objetivo em busca da construção de uma nova esquerda era notável, como afirma Gaspari (2002):

[...] ia buscar uma numa nova esquerda mundial projetos de militância desligados da velha proposição marxista, na qual todas as atividades revolucionárias deveriam confluir para o grande projeto da tomada de poder. Em Opinião havia espaço para as mulheres, os negros e os homossexuais como tais, sem que fizessem parte de uma marcha da humanidade em direção ao socialismo.

O Jornal Politika foi um impresso menos popular e consequentemente temos menos informações a seu respeito, porém, ainda assim, apresenta importantes publicações voltadas para questões críticas existentes no Brasil, como o "milagre econômico". Foi um semanário produzido por "jornalistas cariocas veteranos em cobertura política - Oliveira Bastos, Sebastião Nery, Jorge França e Adirson de Barros" (KUCINSKI, 2001, p. 49). Um impresso de oposição idiossincrática, com pouquíssimas publicidades e propagandas, mas com muitas informações extremamente bem fundamentadas, e com embasamento muito forte na política, na economia, devido a isso utilizava muitos gráficos e tabelas que exibiam dados fundamentados por fontes como Organização das Nações Unidas, Anuários de Estatísticas do Trabalho, Anuários Estatísticos do Brasil. Possuía publicações de grandes professores, escritores e economistas, como Paul Israel Singer e Bresser Pereira. Foi um jornal criado também no Rio de Janeiro, no ano de 1971, tendo pouca duração e circulando apenas até o ano de 1973, sendo fechado principalmente devido à falta de recursos. Kucinski (2001, p. 49) afirma que: 
O Centro de Informações e Segurança da Aeronáutica (CISA), entregou ao governo um dossiê acusando Politika de ser uma 'plataforma de difusão do PCB, MR8 e políticos cassados e exilados' e propondo uma ação combinada de repressão contra o jornal, incluindo a devassa fiscal. Submetido a pressões e à censura prévia, Politika fechou carregado de dívidas.

A partir da análise dos semanários da imprensa alternativa apresentados acima, passamos agora a estudar publicações divulgadas por meio desses impressos para criticar as ações do governo e dar ênfase às situações pelas quais o proletariado era submetida.

\section{A crítica por meio das publicações}

Os jornais se mostravam como ferramentas de resistência perante a situação na qual o Brasil se encontrava, além de estar diretamente comprometido com a classe trabalhadora, também passava a visão e se incluía dentro dessa classe, afinal decorrente disso, sofria dos males proporcionados pelo governo durante o período aqui estudado.

Na Figura 2 notamos como a inflação ocorrida no período do milagre afetou diretamente a redação do jornal Politika, que precisou aumentar o valor de seus impressos, isso fez com que o jornal tivesse que se "explicar" para os leitores, utilizando também um tom de "revolta", insatisfação e de crítica explicita ao governo e ao ministro Delfim Neto, fazendo uma colocação em relação à inflação, em que levanta a questão de que os dados expostos pelo Ministério da Fazenda eram falsos e que a realidade da inflação era muito mais grave do que haviam exposto, como considerado no Politika (1972) “[...] infelizmente a inflação de 14\% do ministro Delfim Neto é só dele e da sua Fundação Getúlio Vargas. A nossa aqui, foi exatamente de 105\% em 1972”.

Os editores buscam fazer com que os leitores se conscientizem da situação na qual o governo estava submetendo a economia brasileira. Vejam: "Pedimos que vocês tenham conosco apenas 50\% dos 100\% de paciência e sofrimento que tivemos em 1972 com a política econômico-financeira do governo" (POLITIKA, 1972).

\section{Figura 2 - O preço de lutar}

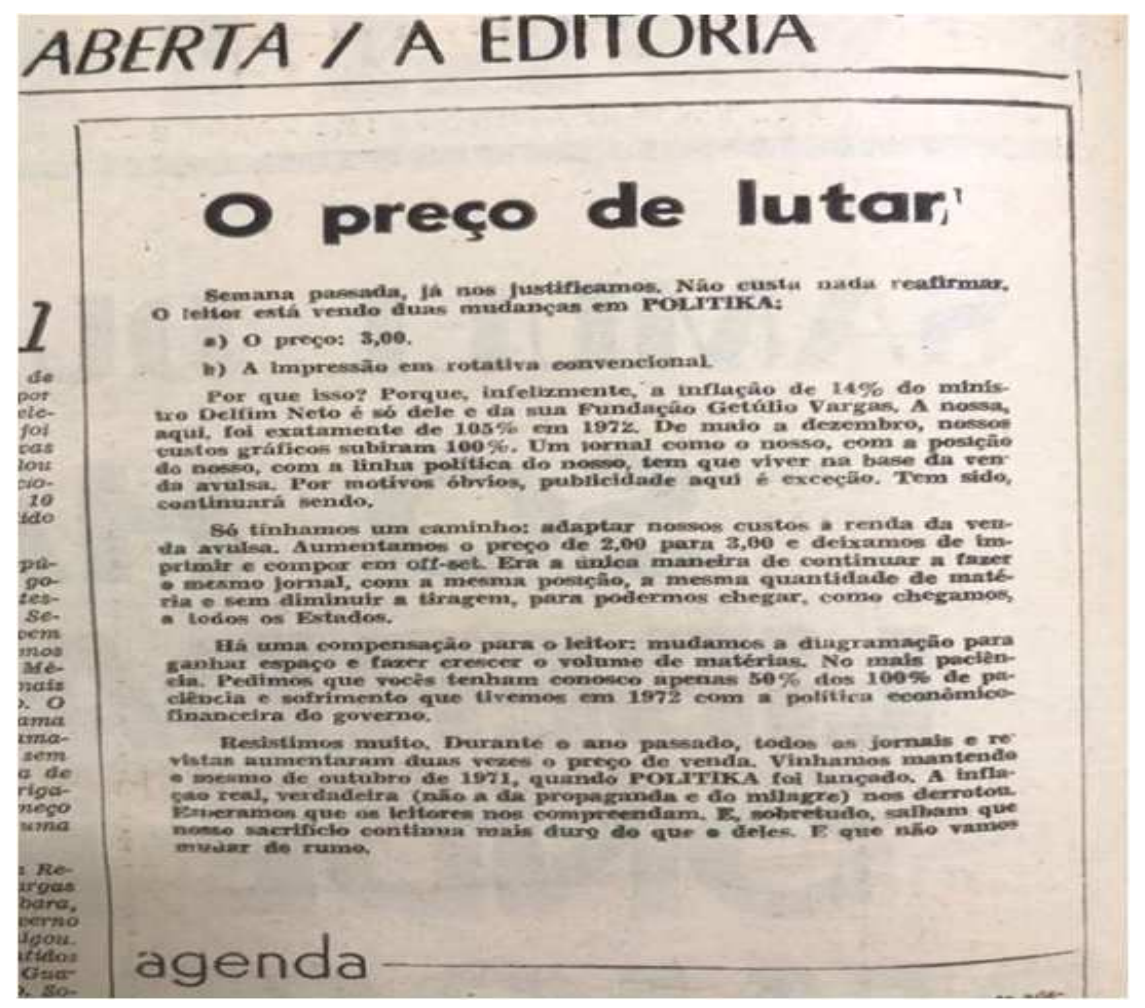

Fonte: Politika(1973). Acervo: D’incao Instituto de Ensino, Bauru, SP. 
Na publicação do Jornal Opinião, apresentada na Figura 3, conseguimos analisar que a redação busca demonstrar como se encontra a vida social do proletariado, em tempos de "milagre econômico", com problemas de desemprego, que automaticamente proporcionava o desamparo e a fome da população, além de diversos surtos de doenças que assolavam a massa de trabalhadores. Observem o trecho de Opinião (1973): "Grande parte da população apenas sobrevive de duras penas, seja no campo, seja na cidade, tendo por companheira a fome e por inquilinos as verminoses intestinais, a malária, a doença de chagas e a esquistossomose".

Em relação à questão econômica, afirma-se em um trecho da imagem que: "Em 1960, os 80\% mais pobres da população economicamente ativa detinham 35\% da renda nacional. Em 1970, esta porcentagem caiu para 27,5\%" (OPINIÃO, 1973), consequentemente passamos a compreender que todo o restante da renda era destinado para apenas $20 \%$ da população.

Continuando com a análise da imagem, conseguimos compreender pela afirmação da publicação que além dos problemas anteriores, contávamos também com um crescimento populacional elevado, vindo principalmente da classe socioeconômica inferior, trazendo assim dificuldades ainda maiores para essa classe social. Desse modo, a própria publicação revela que: "eis a confirmação de que o interesse maior está voltado para a economia do país (como uma entidade abstrata) e quase nada para o bem-estar e a felicidade do povo, que é a razão de ser do Estado e do país" (OPINIÃO,1973).

\section{Figura 3 - O bem-estar social como prioridade}

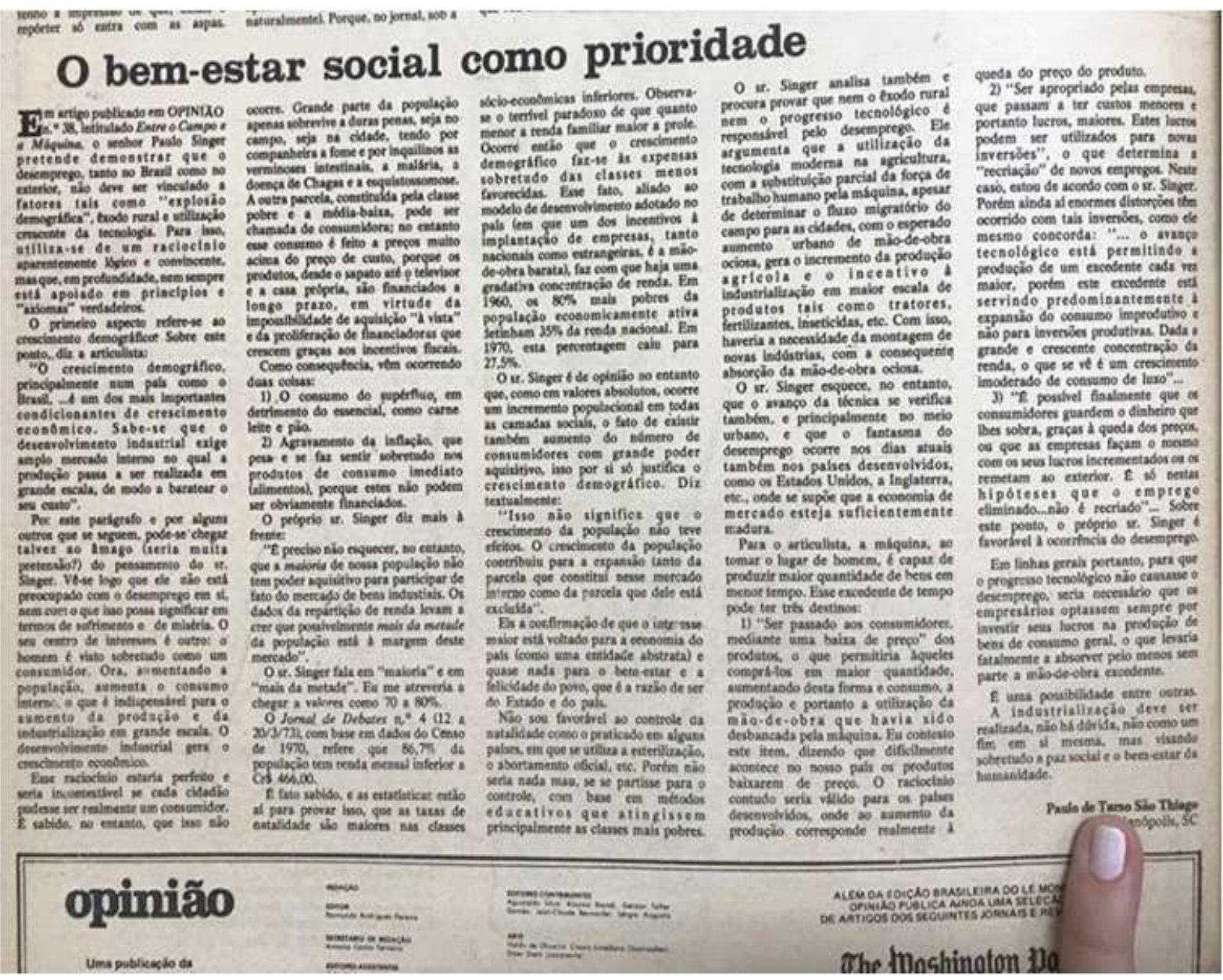

Fonte: São Thiago(1973).

A Figura 4 é uma publicação do Jornal O Pasquim do ano de 1971. Analisando-a, compreendemos que ela busca fazer uma representação de como o governo militar influenciava a sociedade brasileira por meio das propagandas e slogans como "Brasil, ame-o ou deixe-o" e "Brasil Grande". O semanário realiza críticas a essas 
influências governamentais, de modo que se a sociedade deve amar a sua pátria sem contestação, automaticamente sua pátria deveria amá-la também, no entanto esse amor reciproco não existe partindo do governo e das grandes empresas multinacionais que estavam lucrando com a mão de obra barata da classe trabalhadora.

É justamente a partir dessa questão que Ziraldo (cartunista do jornal) expressa sua crítica, representando-a por meio das falas dos personagens quando expressam ou questionam o ideal de amor perante o país. Tomemos como destaque a fala de um dos personagens: "Quem ama, maltrata!" (O PASQUIM, 1971). Esse personagem passa impressão de ser um trabalhador de origem simples, afinal se encontra magro e a conversar com um sujeito da mesma classe, o qual está retratado com pés descalços e rosto surrado, o indivíduo está servindo de acento para um homem maior que ele, viçoso e com roupas sofisticadas, esse homem "sofisticado" pode ser entendido como representação das empresas multinacionais ou do próprio Estado. Logo aí, notamos a crítica do cartunista, mostrando que a classe trabalhadora é explorada e sofre com as atitudes tomadas pelo Estado e pelos grandes empresários, no entanto é alienada pelo discurso nacionalista empregado pelo governo.

Destaca-se também a fala de mais um personagem do cartum: "você já reparou uma coisa? só ama o Brasil quem tem carro..." (O PASQUIM, 1971). Ao observar esse personagem e o indivíduo com quem ele conversa conseguimos detectar que fazem parte da classe trabalhadora, pois são representados com rostos surrados, roupas simples e estão a fazer uma observação crítica expondo o fato que somente pessoas que conseguem ter carros amam o Brasil.

A burguesia brasileira e estrangeira foram as únicas classes favorecidas pelo "milagre econômico". Isso fica evidente aos realizarmos a análise dos dados já apresentados no artigo em relação à quantia da população que recebia um ou menos de um salário mínimo, pois notamos que apenas a classe economicamente superior teria condições de comprar automóveis, afinal a massa de trabalhadores assalariados em si continha apenas o dinheiro para a alimentação mínima mensal, tendo até mesmo que muitas vezes recorrer ao trabalho infantil, dispondo seus filhos ao trabalho para poder completar o sustento da família, como afirmado por Camargo (1976, p. 93 apud HABERT,1992, p. 18):

Os filhos menores são obrigados a abandonar os estudos e são impelidos para empregos mal remunerados ou para as ruas, engrossando o contingente dos que aprendem a "se virar" no mundo marginal. Só na Grande São Paulo, em 1971, 20\% dos menores em idade escolar (dos 7 aos 14 anos) estavam fora da escola.

\section{Figura 4 - O jogo do amor}

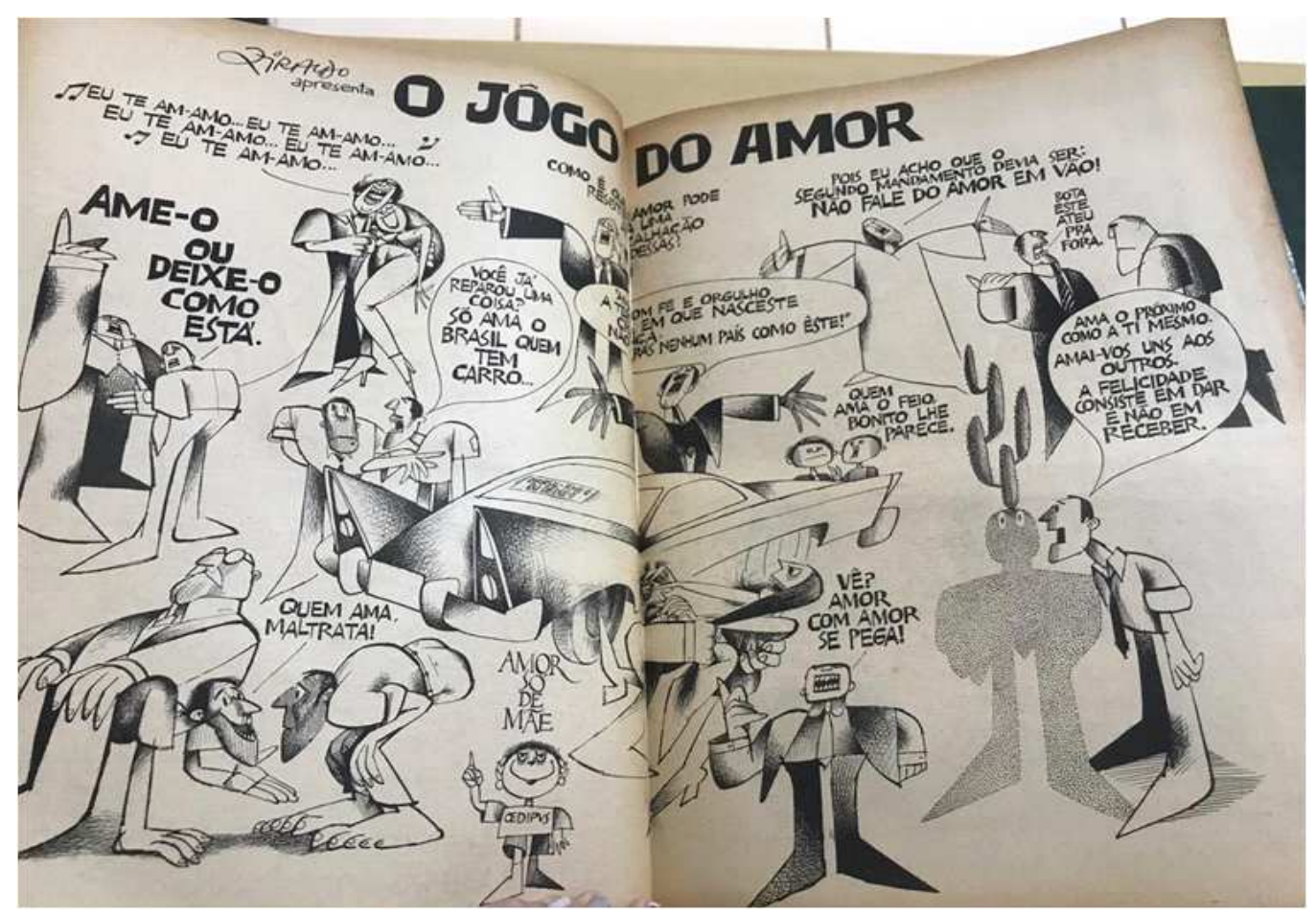

Fonte: O Pasquim(1971). Acervo: D’incao Instituto de Ensino, Bauru, SP. 


\section{Considerações finais}

O chamado "milagre econômico" brasileiro proporcionou crescimento acelerado no país, fazendo com que, dessa forma, diversas empresas multinacionais criassem filiais no Brasil que passaram a ter um alto desempenho de produtividade devido às péssimas condições de trabalho e ausências de direitos trabalhistas.

A análise realizada no presente artigo deixa evidente a compreensão de como a classe trabalhadora era submetida a diversas formas de exploração perante a questão econômica, incluindo, por exemplo, o arrocho salarial que passou a subjugar o trabalhador a horas de trabalho mais extensas para conseguir o valor de alimentação mínima mensal, além de más condições que sujeitavam o proletariado a acidentes de trabalho. Contava também com um governo repressivo e agressivo, que retirava a liberdade de expressão e impossibilitava reivindicações trabalhistas, além de limitar as informações ao público, censurando jornais que buscavam publicar reportagens críticas, dados estatísticos e que dava notoriedade aos trabalhadores da sociedade.

Durante o "milagre econômico", em contrapartida, a questão social foi se agravando cada vez mais, resultando em uma população carente de atenção do Estado, encontrando-se no Brasil altos índices de subnutrição, excessivos dados de acidentes de trabalho, surtos de doenças " verminoses intestinais, malária, doença de chagas e esquistossomose - e a fome.

Com as análises realizadas de jornais da imprensa alternativa e revisão bibliográfica referente à situação socioeconômica do país, ficou evidente que o conhecido "boom" da economia brasileira, estava camuflado pela manipulação do governo, que se dava por meio de divulgações de dados estatísticos alterados, como foi apresentado no decorrer do artigo na publicação do jornal que contesta a divulgação feita pelo Ministério da Fazenda sobre os dados da inflação brasileira.

A partir das análises dos Jornais Politika, Opinião e O Pasquim, semanários que fizeram parte da histórica imprensa alternativa, ficam explícitas as formas pelas quais esses jornais buscaram, por meio de publicações, expor e contestar as atitudes governamentais, as quais acarretavam sérios problemas socioeconômicos sobre a massa de trabalhadores da sociedade. Além das críticas ao sistema, empenhavam-se em dar visibilidade ao proletariado, mostrando, assim, que o Brasil era composto não apenas por dados exatos da economia, mas também por seres humanos, que sofriam com diversos problemas sociais e econômicos devido à situação em que o país se encontrava na época.

Por fim, podemos concluir destacando o fato de que a classe trabalhadora brasileira se encontrou durante todo o período do "milagre econômico" desprovida de atenção do Estado, resultando em uma população carente de bem-estar social, algo considerado incabível, afinal o povo é a razão de ser do Estado e do país.

\section{Referências}

ABREU, J. B. As manobras da informação. Rio de Janeiro: EDUFF, 2000.

AUGUSTO, S., JAGUAR. O melhor do Pasquim. Rio de Janeiro: Desiderata, 2006.

ALVES, M. H. M. Estado e oposição no Brasil 1964-1984. Bauru: EDUSC, 2005.

AYMORE, L. M. O Pasquim no contexto de formação da indústria cultura do Brasil. In: XXIII ENCONTRO ESTADUAL DE HISTÓRIA. São Paulo: 2016. Disponível em: http://www.encontro2016.sp.anpuh.org/resources/anais/48/ 1475258731_ARQUIVO_t23.pdf Acesso em: 17 set. 2019.

CHINEM, R. Imprensa alternativa jornalismo de oposição e inovação. São Paulo: Ática. 1995.

GASPARI, E. Ditadura escancarada. São Paulo: Companhia das Letras, 2002.

GERHARDT, T. E; SILVEIRA, D. T. (org.). Métodos de pesquisa. Porto Alegre: Ed. da UFRGS, 2009. (EAD Série educação a distância).

HABERT, N. A década de 70. São Paulo: Ática, 1992.

KUCINSKI, B. Jornalistas e revolucionários nos tempos da imprensa alternativa. São Paulo: EccentricDuo. 2001. Disponível em: http://kucinski.com.br/pdf/livros_jornrevPrint.pdf. Acesso em: 16 out. 2019.

MACIEL, D. Ditadura militar e capital monopolista: estruturação, dinâmica e legado. Lutas Sociais, São Paulo, v. 18, n. 32, p. 64-78, jan./jun. 2014. Disponível em: https://revistas.pucsp.br/ls/article/view/25692/pdf. Acesso em: 20 nov. 2019.

OLIVEIRA, S. M. F. Os trabalhadores urbanos e a ditadura militar. Revista de Administração Pública, Rio de Janeiro, v. 21, n. 2, p. 2436, abr./jun. 1987.

OPINIÃO. Nove meses de crise. Rio de Janeiro: 1973. Acervo: D’íncao Instituto de Ensino, Bauru, SP.

POLITIKA. O preço de lutar. Rio de Janeiro: 1973. Acervo: D’incao Instituto de Ensino, Bauru, SP.

SÃO THIAGO, P. T. O bem-estar social como prioridade. Opinião, Jornal, Rio de Janeiro: 1973. Acervo: D’́incao Instituto de Ensino, Bauru, SP.

ZIRALDO, A. P. O jogo do amor. O Pasquim, Semanário. Rio de Janeiro: 1971. Acervo: D’incao Instituto de Ensino, Bauru, SP. 


\section{Nota}

1 Expressão utilizada por Habert(1992).

\section{Ana Elisa Lara Paulino}

anaelisapaulino98@gmail.com

Graduada em História pela Universidade do Sagrado Coração (UNISAGRADO)

Professor de História da Rede Estadual de Ensino do Estado de São Paulo

\section{UNISAGRADO}

Rua Irmã Arminda, 10-50, Jardim Brasil

Bauru - São Paulo - Brasil

CEP: $17011-160$

\section{Agradecimentos}

Não se aplica.

Agência financiadora

Não se aplica.

Contribuições das autoras

Não se aplica.
Aprovação por Comitê de Ética e consentimento para participação

Não se aplica.

Consentimento para publicação

Consentimento da autora.

Conflito de interesses

Não há conflito de interesses. 